\title{
Penerapan Model Pembelajaran Kooperatif Tipe Numbereded Heads Together (NHT) Pada Konsep Sistem Pencernaan Makanan Pada Manusia Di Kelas IV SD Negeri Mandalasari 1 Kecamatan Puspahiang Kabupaten Tasikmalaya.
}

\author{
Egi Nuryadin \\ Jurusan Pendidikan Biologi FKIP Universitas Siliwangi \\ Jalan Siliwangi Nomor 24 Tlp. (0265) 323532 Fax. 323532 Tasikmalaya - 46115 \\ e-mail: egi.nuryadin@unsil.ac.id
}

\begin{abstract}
Research aims to understand match / the accuracy of learning model cooperative type Numbered heads \& together ( nht in learning the concept of digestive system food on human beings in fourth grade land mandalasari 1 kecamatan puspahiang the market. A population that used all participants fourth grade students land mandalasari 1 and the Numbered of students 36 people.The whole population of are only sampled the school tuition fourth grade land mandalasari 1 in 36 people.An instrument used in this research was the test results student learning the concept digestive system food in humans.

This test of tests the form of an option double with 4 option. Analysis techniques the data used was the median $t$ and tests. The results showed based on analysis of the median test scores me is greater than values me determined. So the application of learning model cooperative type Numbered heads together (nht) match is applied to explain the digestive system food on human beings in fourth grade mandalasari 1 .
\end{abstract}

Keywords: Cooverative learning model, Numbereded heads together, cognitive learning result

\begin{abstract}
Abstrak
Penelitian ini bertujuan untuk mengetahui kecocokan/ketepatan model pembelajaran kooperatif tipe Numbered Heads Together (NHT) pada proses pembelajaran konsep Sistem Pencernaan Makanan pada Manusia di kelas IV SD Negeri Mandalasari 1 Kecamatan Puspahiang Kabupaten Tasikmalaya. Populasi yang digunakan seluruh peserta didik kelas IV SD Negeri Mandalasari 1 dengan jumlah siswa 36 orang. Seluruh populasi dijadikan sampel yaitu peserta didik kelas IV SD Negeri Mandalasari 1 sebanyak 36 orang. Instrumen yang digunakan dalam penelitian ini adalah tes hasil belajar siswa pada konsep sistem pencernaan makanan pada manusia. Tes ini berupa tes bentuk pilihan ganda dengan 4 option. Teknik analisis data yang digunakan adalah Uji t dan tes median. Hasil penelitian menunjukan berdasarkan analisis tes median nilai Me yang sebenarnya lebih besar daripada nilai Me yang ditentukan. Sehingga penerapan model pembelajaran kooperatif tipe Numbered Heads Together (NHT) cocok diterapkan untuk menjelaskan konsep Sistem Pencernaan Makanan pada Manusia di kelas IV SD Negeri Mandalasari 1.
\end{abstract}

Kata Kunci: Model pembelajaran kooperatif, Numbereded heads together, hasil belajar kognitif 


\section{PENDAHULUAN}

Dengan berkembangnya ilmu pengetahuan dan kemajuan IPTEK yang semakin maju, maka manusia dituntut untuk mampu bersaing di era globalisasi ini. Dengan belajar menggunakan tekhnologi itu untuk memperoleh pengetahuan yang lebih luas terutama dalam pendidikan yang pada saat ini semakin maju. Maka untuk mengimbangi pendidikan yang maju itu diperlukan sumberdaya manusia yang baik, yang memiliki kompetensi dalam segala bidang yang nantinya mampu berkompetisi dan mampu mengimbangi kemajuan ilmu pendidikan.

Pendidikan merupakan hal yang sangat penting dalam kehidupan, baik dalam kehidupan seseorang, keluarga, bahkan bangsa dan negara. Pendidikan dilaksanakan secara sadar untuk mengembangkan potensi seorang anak menjadi pribadi yang dewasa, memiliki kecerdasan, keterampilan dan memupuk budipekerti, sehingga pada akhirnya dapat mewujudkan tanggung jawab terhadap diri sendiri dan orang lain.

Proses pendidikan yang ideal adalah proses pendidikan yang dikemas dengan memperhatikan adanya berbagai aspek, yaitu aspek kognitif, afektif dan aspek psikomotorik. Apabila proses pendidikan dapat dilaksanakan dengan memperhatikan adanya keseimbangan ketiga aspek tersebut maka output pendidikan akan mampu mengantisipasi perubahan dan kemajuan masyarakat.
Sekolah sebagai lembaga pendidikan menyelenggarakan kegiatan belajar mengajar dengan tujuan mengembangkan kecakapan minat, bakat dan motivasi dari anak didik secara optimal sehingga mereka dapat bertanggung jawab terhadap individunya dan masyarakat. Melalui kegiatan pembelajaran, akan tercipta interaksi dan komunikasi timbal balik antara guru dengan peserta didik yang merupakan ciri dan syarat utama bagi berlangsungnya proses belajar mengajar. Untuk mendukung hal tersebut guru harus memperhatikan faktor dan komponenkomponen dalam kesiapan pembelajaran di antaranya kesiapan dirinya sendiri, keadaan peserta didik, model, alat-alat peraga atau media serta sumber-sumber belajar lainnya.

Untuk menciptakan hasil belajar yang baik, maka perlu adanya pembaharuan pendidikan secara terencana, terarah dan berkesinambungan. Karena salah satu masalah dalam pendidikan yaitu lemahnya proses pembelajaran. Sehingga hasil dari proses pembelajaran itu tidak sesuai dengan harapan. Guru harus menjadi pembimbing peserta didik, dan mengarahkan peserta didik dalam proses pembelajaran yaitu harus menjadi motivator bagi peserta didik. Selain itu guru harus menerapkan / menggunakan model pembelajaran yang bisa memotivasi peserta didik untuk lebih baik dalam proses pembelajaran. Tetapi pada kenyataannya, 
model pembelajaran yang ada kurang sekali dipergunakan, sehingga peserta didik pun kurang kreatif dan inovatif dalam proses pembelajaran. Padahal untuk menciptakan suasana yang aktif, kreatif, dan inovatif ketika proses pembelajaran berlangsung, guru perlu menggunakan macam-macam model pembelajaran supaya anak tidak merasa bosan.

Berdasarkan hasil wawancara dengan guru di SDN Mandalasari 1 Kecamatan Puspahiang Kabupaten Tasikmalaya pada tanggal 12 Desember 2011, guru di sekolah tersebut selama ini jarang menggunakan macam-macam model pembelajaran, khususnya pada materi Sistem Pencernaan Makanan pada Manusia.

Dari latar belakang tersebut penulis berupaya untuk melakukan penelitian dengan menerapkan model pembelajaran kooperatif tipe Numbered Heads Together (NHT) pada konsep Sistem Pencernaan Makanan pada Manusia di kelas IV SD Negeri Mandalasari 1 Kecamatan Puspahiang Kabupaten Tasikmalaya, yang nantinya diharapkan adanya keaktifan dalam proses pembelajaran dan suasana kelas menjadi menyenangkan buat peserta didik, sehingga pada akhirnya dapat memotivasi peserta didik untuk belajar.

Berdasarkan latar belakang masalah tersebut, dapat diidentifikasi masalah sebagai berikut :

1. apakah peserta didik dapat mengikuti pembelajaran dengan menggunakan model pembelajaran kooperatif tipe Numbered Heads Together (NHT)?;

2. apakah peserta didik tertarik dengan model pembelajaran kooperatif tipe Numbered Heads Together (NHT)?;

3. apakah model pembelajaran kooperatif tipe Numbered Heads Together (NHT) dapat meningkatkan pemahaman peserta didik?; dan

4. apakah model pembelajaran kooperatif tipe Numbered Heads Together (NHT) cocok diterapkan untuk menjelaskan Konsep Sistem Pencernaan Makanan pada Manusia?.

Agar permasalahan yang diteliti tidak terlalu meluas, maka penulis membatasi masalah sebagai berikut :

1. penelitian ini hanya untuk mengukur dan mengetahui hasil belajar peserta didik dengan menerapkan model pembelajaran kooperatif tipe Numbered Heads Together (NHT);

2. hasil belajar peserta didik adalah kemampuan kognitif peserta didik tentang Sistem Pencernaan Makanan pada Manusia yang terdiri atas tingkatan mengingat $\left(\mathrm{C}_{1}\right)$, memahami $\left(\mathrm{C}_{2}\right)$, dan menerapkan $\left(\mathrm{C}_{3}\right)$ setelah peserta didik melakukan pembelajaran dengan menggunakan model pembelajran kooperatif tipe Numbered Heads Together (NHT), hasil belajar peserta didik dinyatakan oleh skor 
yang didapat peserta didik setelah menempuh tes hasil belajar pada konsep Sistem Pencernaan Makanan pada Manusia;

3. materi yang diberikan hanya pada Sistem Pencernaan Makanan pada Manusia; dan

Berdasarkan uraian tersebut, peneliti tertarik untuk mengadakan penelitian tentang penerapkan model pembelajaran kooperatif tipe Numbered Heads Together (NHT) pada konsep Sistem Pencernaan Makanan pada Manusia di kelas IV SD Negeri Mandalasari 1.

\section{METODE PENELITIAN}

1. Metode penelitian

Penelitian ini menggunakan metode pre-eksperimen. Penelitian menggunakan satu kelas tanpa kelas kontrol. Menurut Sugiyono (2011:74) "Metode penelitian pre-eksperimental tidak adanya variabel kontrol dan sampel tidak dipilih secara random". Data yang diperoleh kemudian di analisis secara statistik dengan membandingkan hasil pretest dan posttest.

2. Variabel penelitian

Variabel yang digunakan yaitu:

a. Variabel bebas dalam penelitian ini adalah model pembelajaran. Adapun variabel bebas yang dimaksud adalah model pembelajaran kooperatif tipe Numbered Heads Together (NHT) b. Variabel terikat dalam penelitian ini adalah hasil belajar peserta didik.

\section{Definisi operasional}

a. Supaya tidak terjadi kesalahpahaman, yang dimaksud model pembelajaran kooperatif tipe Numbered Heads Together (NHT) adalah salah satu tipe pembelajaran kooperatif yang menekankan pada struktur khusus yang dirancang untuk mempengaruhi pola interaksi peserta didik dan memiliki tujuan untuk meningkatkan penguasaan akademik. Tipe ini melibatkan para peserta didik dalam menelaah bahan yang tercakup dalam suatu pelajaran dan mengecek pemahaman mereka terhadap isi pelajaran tersebut.

Adapun langkah-langkahnya sebagai berikut :

1) guru membagi peserta didik menjadi 5 kelompok, setiap kelompok terdiri dari 8 orang, kemudian peserta didik dalam setiap kelompok mendapatkan nomor 1-8;

2) peserta didik duduk sesuai dengan kelompoknya masing-masing;

3) setiap peserta didik yang telah mendapatkan nomor, nomornya diikatkan di kepala;

4) guru memberikan tugas berupa LKPD kepada peserta didik dan 
masing-masing kelompok mengerjakannya;

5) setiap kelompok mendiskusikan jawaban yang dianggap benar kemudian memastikan tiap anggota kelompoknya dapat mengerjakannya;

6) guru memanggil salah satu nomor yang sama dari tiap-tiap kelompok, kemudian peserta didik diberi kesempatan untuk melaporkan hasil kerjasamanya;

7) peserta didik memberikan tanggapan terhadap jawaban yang diutarakan, kemudian guru akan menunjuk nomor yang sama dari tiap-tiap kelompok, dan seterusnya;

8) guru memberikan penekanan materi esensial dan meluruskan persepsi tentang tugas yang diberikan dengan menggunakan persentasi slide show; dan

9) guru membimbing peserta didik dalam membuat kesimpulan.

b. Hasil belajar merupakan kemampuan peserta didik setelah memperoleh pengalaman dan berinteraksi dengan lingkungannya. Hasil belajar digunakan dalam penelitian ini dibatasi pada ranah kognitif yaitu berupa skor hasil belajar pada materi sistem pencernaan pada manusia dengan penilaian kognitif yang meliputi $\mathrm{C} 1$ (remembering), C2 (understanding), C3 (applying).

c. Populasi dan sampel

1. Populasi

Populasi dalam penelitian ini adalah seluruh peserta didik kelas IV SDN Mandalasari 1 Kecamatan Puspahiang Kabupaten Tasikmalaya dengan jumlah peserta didik 36 orang yaitu laki-laki 17 orang dan perempuan 19 orang.

2. Sampel

Sampel dalam penelitian ini adalah peserta didik kelas IV SD Negeri Mandalasari 1. Karena metode penelitian yang digunakan adalah preeksperimen maka sampel diambil dengan teknik Sampling Jenuh.

d. Desain penelitian

Desain penelitian ini adalah dengan menggunakan one group pretest-posttest design. Dalam penelitian ini peneliti menggunakan satu kelompok subjek. Pada awal penelitian dilakukan pengukuran (pretest) kemudian dilakukan perlakuan (treatment) untuk jangka waktu tertentu. Setelah itu, dilakukan pengukuran untuk kedua kalinya (posttest).

Rancangan one group pretestposttest menurut Sugiyono, (2011: 74) adalah sebagai berikut:

$$
0_{1} \mathrm{X}_{2}
$$


Keterangan :

$\mathrm{O}_{1} \quad$ : pengukuran awal (pretest)

$\mathrm{X}$ : perlakuan (treatment) dengan menggunakan model pembelajaran kooperatif tipe Numbered

\section{Heads Together (NHT)}

$\mathrm{O}_{2} \quad$ : pengukuran akhir (posttest)

\section{e. Teknik Pengumpulan Data}

Teknik pengumpulan data dalam penelitian ini adalah teknik tes tertulis. Karena dalam penelitian penulis melakukan observasi dengan menggunakan instrumen berupa tes tertulis dalam bentuk pilihan ganda dengan 4 option.

f. Instrumen penelitian

Instrumen yang digunakan dalam penelitian ini adalah tes hasil belajar peserta didik pada konsep sistem pencernaan makanan pada manusia dengan jumlah soal sebanyak 50 soal. Tes berbentuk pilihan ganda dengan 4 option. Aspek yang diukur hanya dominan kognitif dan dibatasi atas tingkatan $\mathrm{C} 1$ (remembering), C2 (understanding), C3 (applying). Selanjutnya soal yang jawabannya benar diberi skor ditambah satu (+1) dan jawaban yang salah diberi skor nol (0).

g. Uji coba instrumen

Uji coba instrumen dilaksanakan di kelas V SD Negeri Palasari Kecamatan Puspahiang Kabupaten Tasikmalaya, pada tanggal 16 Pebruari 2012 pukul 07.30 s/d $09.00 \mathrm{WIB}$.

h. Analisis data

1) Uji Persyaratan

a) Uji normalitas dengan menggunakan uji chi kuadrat

b) Uji homogenitas dengan menggunakan uji $\mathrm{F}_{\text {Maksimum }}$

2) Uji Hipotesis

Data hasil Pretest dan posttest, yang menggunakan model pembelajaran kooperatif tipe Numbered Heads Together (NHT), masing-masing dikelompokkan ke dalam daftar distribusi frekuensi, dan selanjutnya dilakukan analisis data dengan menggunakan uji $\mathrm{t}$ untuk melihat perbedaan hasil pretest dan posttest. Data hasil posttest diuji dengan uji median untuk mengetahui apakah ratarata hasil belajar sama atau lebih besar dari KKM.

i. Waktu Penelitian

1. Tempat penelitian Penelitian dilaksanakan di kelas IV SD Negeri Mandalasari 1 Kecamatan Puspahiang Kabupaten Tasikmalaya.

2. Waktu penelitian Waktu penelitian dilaksanakan pada bulan Desember 2011 - April 2012 mulai dari tahap persiapan sampai akhir. 
Bioedusiana

Volume 01, Nomor 01, September 2016

ISSN 2477-5193

\section{HASIL DAN PEMBAHASAN}

Berdasarkan hasil analisis Data hasil belajar Peserta didik kedua kelompok berasal dari populasi yang berdistribusi normal dan kedua varians homogen, sehingga untuk membandingkan data hasil pretest dan posttest digunakan adalah uji t.

Hipotesis yang diuji adalah :

$\mathrm{H}_{\mathrm{o}} \quad$ : Hasil pretest sama dengan hasil posttest.

$\mathrm{H}_{\mathrm{a}}$ : Hasil pretest tidak sama dengan hasil posttest.

Kaidah pengujian hipotesis yang digunakan adalah :

Terima $\mathrm{H}_{0}$ jika $\mathrm{t}_{\text {tabel }}<\mathrm{t}_{\text {hitung }}<\mathrm{t}_{\text {tabel }}$

Hasil analisis $t_{\text {hitung }}-11,98$ dan $t_{\text {tabel }} 2,03$ dapat digambarkan sebagai berikut :

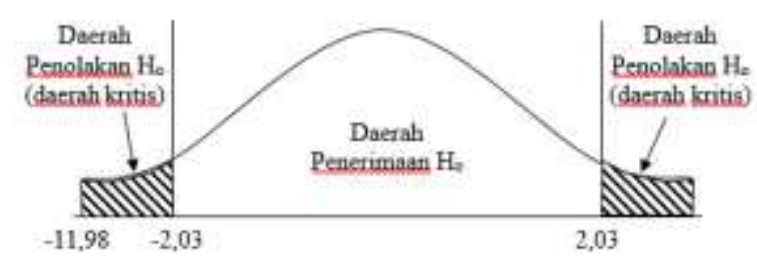

\section{Gambar 1 \\ Diagram Hasil Uji t}

diketahui bahwa $\mathrm{t}_{\text {hitung }}=-11,98$ terletak di daerah penolakan $\mathrm{H}_{0}$. Dengan demikian, hipotesis yang penulis ajukan yaitu "Hasil pretest tidak sama dengan hasil posttest" diterima. Hasil rata-rata pretest adalah $(\overline{\mathrm{X}}=12,56)$ dan hasil rata-rata posttest adalah $(\bar{X}=19,39)$. Maka dari data tersebut hasil posttest lebih baik dari hasil pretest.

Untuk mengetahui apakah model pembelajaran kooperatif tipe Numbered Heads Together (NHT) cocok diterapkan pada proses pembelajaran konsep Sistem Pencernaan Makanan Pada Manusia di kelas IV SD Negeri Mandalasari 1 Kecamatan Puspahiang Kabupaten Tasikmalaya diuji dengan uji median.

Hipotesis yang akan diuji adalah :

$$
\begin{aligned}
\mathrm{H}_{\mathrm{o}} \quad: & \text { Median hasil post-test sama } \\
& \text { dengan median yang telah } \\
& \text { ditentukan } \\
\mathrm{H}_{\mathrm{a}}: & \text { Median hasil post-test tidak } \\
& \text { sama dengan median yang } \\
& \text { telah ditentukan }
\end{aligned}
$$

Kaidah pengujian hipotesis yang digunakan adalah :

\begin{tabular}{|c|c|c|c|c|c|}
\hline $2 p$ & $a$ & $\begin{array}{c}\text { Hand } \\
\text { Aualisis }\end{array}$ & Kesienpulan & $\begin{array}{c}\text { Median } \\
\text { Sesuaguhays }\end{array}$ & $\begin{array}{l}\text { Median } \\
\text { yaug tebl } \\
\text { ditantulan }\end{array}$ \\
\hline 0,0006 & 0,05 & $2 p<a$ & Tolak $\mathrm{H}_{0}$ & 16,25 & 19,5 \\
\hline
\end{tabular}

Tolak $\mathrm{H}_{0}$ jika $2 p \leq \alpha$ dengan $p=$ probabilitas

\section{Hasil analisis dapat dilihat pada tabel berikut: Tabel 1 Ringkasan Hasil Tes Median}

Berdasarkan Tabel 4.9 di atas, diperoleh nilai $2 p=$ 0,0006 dan $\quad \alpha=0,052 p<\alpha$. Maka, hipotesis yang penulis ajukan yaitu median hasil post-test tidak sama dengan median yang ditentukan. Hal ini menunjukan bahwa KKM telah dicapai. Jadi model pembelajaran kooperatif tipe Numbered Heads Together cocok diterapkan untuk menjelaskan konsep Sistem Pencernaan Makanan pada Manusia di kelas IV SD Negeri Mandalasari 1 Kecamatan Puspahiang Kabupaten Tasikmalaya. 
Model pembelajaran kooperatif tipe Numbered Heads Together (NHT) merupakan salah satu tipe pembelajaran kooperatif yang menekankan pada struktur khusus yang dirancang untuk mempengaruhi pola interaksi peserta didik dan memiliki tujuan untuk meningkatkan penguasaan akademik. Dan pada proses pembelajarannya peserta didik semangat untuk belajar berkelompok, dengan adanya nomor yang diikatkan di kepala peserta didik merasa nyaman dan seru dalam pembelajarannya. Kemudian mereka saling bertukar pikiran dalam menyelesaikan soal LKPD yang diberikan oleh guru sehingga semua peserta didik mengetahui semua jawaban yang ada dalam LKPD. Dan ketika guru menunjuk salah satu nomor, peserta didik sudah siap untuk mempersentasikannya di depan kelas.

Model pembelajaran kooperatif tipe Numbered Heads Together (NHT) ini memiliki banyak sekali kelebihan, yaitu peserta didik menjadi siap dalam belajar, dan apabila ada yang tidak dimengerti mereka saling bekerja sama sehingga peserta didik yang kurang pandai diajari oleh peserta didik yang pandai dan semua peserta didik berdiskusi secara sungguh-sungguh sehingga semua peserta didik bisa menguasai materi yaitu Sistem Pencernaan Makanan pada Manusia. Dilihat dari hasil perhitungan sebelumnya hasil belajar peserta didik sesudah proses pembelajaran dengan menggunakan model pembelajaran kooperatif tipe Numbered heads Together (NHT) mempunyai nilai rata-rata lebih besar dari pada hasil belajar peserta didik sebelum proses pembelajaran dengan menggunakan model pembelajaran kooperatif tipe Numbered heads
Together (NHT). Sehingga model pembelajaran kooperatif tipe Numbered heads Together (NHT) cocok diterapkan untuk menjelaskan konsep Sistem Pencernaan Makanan pada Manusia di kelas IV SD Negeri Mandalasari 1 Kecamatan Puspahiang Kabupaten Tasikmalaya.

\section{SIMPULAN DAN SARAN}

1. Simpulan

Berdasarkan hasil analisis data dapat disimpulkan bahwa model pembelajaran kooperatif tipe Numbered Heads Together (NHT) cocok diterapkan pada proses pembelajaran konsep Sistem Pencernaan Makanan pada Manusia di kelas IV SD Negeri Mandalasari 1 Kecamatan Puspahiang Kabupaten Tasikmalaya.

2. Saran

a. Dalam penerapan model pembelajaran khususnya model pembelajaran kooperatif tipe Numbered Heads Together (NHT) hendaknya guru membimbing proses diskusi agar sasaran dari diskusi dapat tercapai, dan guru juga diharapkan dapat mengalokasikan atau merencanakan waktu pada setiap langkahnya, agar proses pelaporan hasil kerja dapat dioptimalkan.

b. Guna mengefektifkan proses pembelajaran hendaknya guru dapat memodifikasi mekanisme suatu model pembelajaran tanpa membuang unsur 
pokok model pembelajaran yang digunakan sehingga dapat tercapainya tujuan pembelajaran yang sesuai dengan kriteria ketuntasan minimal yang ada.

c. Bagi peneliti selanjutnya, hendaknya mencoba menerapkan model pembelajaran kooperatif tipe Numbered Heads Together (NHT) pada konsep atau materi yang lain.

\section{DAFTAR PUSTAKA}

Anderson, L.W., \& Krathwohl, D.R. (Eds). (2001). A Taxonomy for learning teaching and assesin: a revision of bloom's taxonomy of educational objectives. A bridged edition. New York:Longman.

Arikunto, Suharsimi. 2010. Prosedur penilaian suatu pendekatan praktek. Jakarta: Rineka Cipta.
Huda, Miftahul. (2011). Cooperative Learning Metode, Teknik, Struktur dan Model Penerapan. Yogyakarta: Pustaka Pelajar.

Isjoni. (2011). Pembelajaran Kooperatif Meningkatkan Kecerdasan Komunikasi Antar Peserta Didik. Yogyakarta: Pustaka Pelajar

Sugiyono. 2003. Statistik untuk penelitian. Bandung:Alfabeta.

Sugiyono. 2012. Metode penelitian kuantitatif, kualitatif dan $R \& D$. Bandung: alfabeta

Suprijono, Agus. (2011). Cooperative Learning Teori dan Aplikasi PAIKEM. Yogyakarta: Pustaka Pelajar.

Syah, Muhibin. (2010). Psikologi Pendidikan dengan Pendekatan Baru (Edisi Revisi). Bandung: PT. Remaja Rosdakarya.

Trianto. (2011). Mendesain Model Pembelajaran Inovatif Progresif. Jakarta: Prenada Media Group.

Wina, Sanajaya. 2010. Strategi pembelajaran berorientasi standar proses pendidikan. Jakarta: Kencana

Yamin, Martinis. (2008). Paradigma Pendidikan Kontruktivistik. Jakarta: Gaung Persada Press. 